\section{Influence of Persistence or Cognitive (In)flexibility in Treatment to Quit Smoking}

\section{Francisca López-Torrecillas ${ }^{1,3 *}$, Maria Mar Rueda ${ }^{2}$, Carlos Herruzo Pino ${ }^{1}$ and María Fernández-García ${ }^{1}$}

${ }^{1}$ The Center for Mind Research, Brain and Behavior (CIMCYC), Universidad de Granada, Spain

${ }^{2}$ Departamento de Estadística e Investigación Operativa, Universidad de Granada, Spain

${ }^{3}$ Department of Personality, Evaluation and Psychological Treatment, School of Psychology, Campus Universitario de Cartuja s/n, Universidad de Granada, Spain

\begin{abstract}
\section{Introduction}

Tobacco use is harmful to health and has been identified as the $2^{\text {nd }}$ most common cause of avoidable mortality. The data collected so far through existing surveillance systems suggest that by 2030 there will be more than 8 million tobacco-related deaths every year. Largely, because of several factors such as the rising smoking rates among youth, particularly among girls, the high risk of uptake of smoking by non-smokers, increased exposure to second hand smoke, and hidden or indirect marketing of tobacco products. Its effects are cumulative throughout life, and it is estimated that about $20 \%$ of the population smokes among adults (aged 16 and over). Studies have highlighted that personality plays an important role in the predisposition, initiation or perpetuation of tobacco abuse or dependence behaviors. The purpose of this study was to analyze the relationship between personality variables prior to the intervention, and remaining abstinent for 12 months in people who had undergone a treatment program to quit smoking.

\section{Methods}

The participants were 125 workers at the University of Granada (50 men and 75 women), with an age average of 46.91 years $(S D=8.15)$, who were recruited through consecutive admissions to an occupational health clinic providing smoking cessation treatment between 2009 and 2012. Participants were
\end{abstract}

*Corresponding author: Francisca López Torrecillas, Department of Personality, Evaluation and Psychological Treatment, School of Psychology, Campus Universitario de Cartuja s/n, Universidad de Granada, 18071 Granada, Spain, Tel: +34 958249557; E-mail: fcalopez@ugr.es

Citation: López-Torrecillas F, Rueda MM, Pino CH, Fernández-García M (2015) Influence of Persistence or Cognitive (In)flexibility in Treatment to Quit Smoking. J Addict Addictv Disord 2: 006.

Received: January 13, 2015; Accepted: March 19, 2015; Published: April 02 , 2015

Copyright: (c) 2015 López-Torrecillas F, et al., This is an open-access article distributed under the terms of the Creative Commons Attribution License, which permits unrestricted use, distribution, and reproduction in any medium, provided the original author and source are credited. assessed with the Temperament and Character Inventory Revised (TCl-R).

Results

The Kaplan-Meier survival analysis was performed to assess the probability of continued abstinence; log-rank tests were used to analyze differences in continued abstinence according to different categorical personality variables. The results revealed that Persistence (or cognitive inflexibility) had a significant influence on survival time, where the group with low scores on persistence, have less probability of relapse and a longer abstinence time than the groups who present medium and high scores on persistence. No significant differences were found on the rest of personality dimensions.

\section{Conclusion}

Our results make it possible to conclude that there are different tobacco abstinence patterns depending on personality profile.

Keywords: Persistence; Personality; Quit smoking treatment

\section{Introduction}

Tobacco use is harmful to health and has been identified as the $2^{\text {nd }}$ most common cause of avoidable mortality. The data collected so far through existing surveillance systems suggest that by 2030 there will be more than 8 million tobacco-related deaths every year. Largely, this will happen due to several factors such as the rising smoking rates among youth, particularly among girls, the high risk of uptake of smoking by non-smokers, increased exposure to secondhand smoke, and hidden or indirect marketing of tobacco products. Its effects are cumulative throughout life, and it is estimated that about $20 \%$ of adult population smokes (aged 16 and over) $[1,2]$. Moreover, personality plays an important role in predisposition, initiation or perpetuation of tobacco abuse or dependence behaviors [3].

In the 1980s, Cloninger [4] proposed a theoretical model of temperamental personality dimensions based on the integration of behavioral genetics data and longitudinal, psychometric, neuro-pharmacological and neuroanatomical studies. His proposal contains four temperament dimensions: Novelty Seeking (NS), Harm Avoidance (HA), Reward Dependence (RD) and Persistence (PS). These dimensions reflect variations in the cerebral monoaminergic systems of activation, inhibition and maintenance of behavior. The first dimension, (NS), expresses the tendency to respond to novel stimuli and reward signals, based on dopaminergic mechanisms of behavioral activation. The second dimension, (HA), is characterized by the tendency to respond intensely to signals of punishment or non-reward, based on serotonergic inhibition systems. The third dimension, $(\mathrm{RD})$, represents the tendency to put into practice approach behaviors and attachment reactions, and maintains behaviors associated with rewards or harm avoidance, with its neurobiological support being the noradrenergic projection system on cerebral areas. Finally, the fourth dimension, (PS), or cognitive inflexibility, is also related to the noradrenergic system. Moreover, the model is extended by adding three character dimensions: Self-Directedness (SD), Cooperativeness (C) and Self-Transcendence (ST), which are more linked to experiential and learning factors.

The model was initially developed for the study of alcoholism, although it can also provide a useful framework to study the role of 
personality in smoking behavior, and it is especially significant tobacco addiction due to four reasons. First, the behaviors highlighted in the seven dimensions of the model are conceptually relevant in the initiation and maintenance of the dependence on nicotine. For example, impulsive people (high score on NS) can present greater frustration when the nicotine reward is restricted, thus experiencing a greater negative effect of tobacco abstinence. Impulsivity is a variable that has been associated with drug use. This association is analyzed from two different paradigms, one considering it as a trait and the other based on its behavioral correlates, such as disinhibition and impulsive decision-making in outpatient smoking treatment (maintained abstinence, relapse and dropout). Individual differences in temperament and impulsivity are increasingly recognized as powerful predictors of addiction treatment outcomes, including smoking cessation ones [5]. Specifically, temperament measures such as novelty seeking and reward dependence predict smoking cessation treatment retention, whereas persistence, non-planning impulsivity and poor decision-making predict smoking relapse [6]. Therefore, smokers (compared to non-smokers) have been found to present higher scores on NS and HA $[7,8]$.

Second, the model considers the relationship between the genotypes and smoking behaviours; in this sense, the effect of the D4 dopamine receptor genotype on smoking behaviors has been shown to be mediated by NS [9]. Third, the systems that intervene in the process and respond to appetitive, aversive and novel stimuli, and that are related to the temperament dimensions of the Cloninger model, can be the basis for smoking behaviors; specifically, the response to aversive stimuli, such as physical sensations of nicotine abstinence, can be exaggerated in individuals with specific personality profiles [10]. Finally, the fourth dimension, the correlations found between pharmacology and temperament dimensions of the Cloninger model, can explain the physiopathology of nicotine addiction. In fact, the dopaminergic and serotoninergic systems related to NS and $\mathrm{HA}$, are associated with nicotine abstinence [11]. Smoking behaviour is affected by a combination of genetic and environmental factors. Genetic factors are known to play a key role in some aspects of smoking behaviour. The association between specific genetic variants and the molecular mechanisms underlying the behavioral phenotypes of nicotine addiction with a focus on dopaminergic transmissions. Nicotine activates the mesolimbic dopaminergic system and mediates positive reinforcing reward effects, primarily by releasing dopamine in the nucleus accumbens [10]. Some studies [12-14] have shown that polymorphisms of the ankyrin repeat and kinase domain containing 1 gene (ANKK1), which is adjacent to the dopamine D2 receptor gene (DRD2), dopamine transporter (SLC6A3) and cytochrome P450 2A6 (CYP2A6) gen influence on smoking cessation and nicotine dependence [14]. Likewise, SLC6A3 10r allele and CYP2A6 polymorphism are linked to nicotine dependence. Therefore, some associated genes such us cytochrome P450 subfamily polypeptide 6 (CYP2A6), dopamine $\mathrm{D}(1), \mathrm{D}(2)$, and $\mathrm{D}(4)$ receptors, dopamine transporter, and serotonin transporter are involved in neurotransmission in relation to smoking [15]. In addition, serotonin transporter has been associated with specific personality traits, such as novelty seeking and harm avoidance [16]. For example, it has been shown that smokers higher scores on NS show greater effects on abstinence symptoms, which may include severe craving for nicotine, irritability, anxiety, loss of concentration, restlessness, decreased heart rate, depressed mood, impatience, insomnia, increased appetite and weight gain.
Therefore, it can be deduced that smokers with different temperaments present different patterns of acute tobacco abstinence, so that they could benefit from treatments adapted to their specific abstinence profiles [17]. The persistence dimension is perhaps the most widely studied one from the behavioral and neurophysiological point of view, both in animals and in humans [18]. This dimension refers to tendency of certain behaviours to persevere in spite of the lack of immediate external reinforcements or in conditions of partial reinforcement. It makes possible to differentiate individuals according to their level of resistance to extinction. Persistence is related to individual differences in hedonic responses and to decision-making related to obtaining incentives [18,19]. The Bechara group [19] suggested that people addicted to substances are people who show alterations in this type of dimension. In addition, their neuroanatomical bases coincide with those that connect the orbitofrontal regions with the subcortical structures that regulate positive and negative emotions (nucleus accumbens and amygdala). The functional disconnection between the two structures, as pointed out by Damasio [20], can be the mechanism that explains, at least partly, the pathology of both persistent behaviours and tobacco addiction. In this sense, studies have shown that smokers who are in treatment and present high scores on persistence are especially vulnerable to relapses [21-25]. There is no existing longitudinal study that relates personality variables from the Cloninger model to the treatment prognosis (abstinence versus relapse). Therefore, the purpose of this study is to analyze the relationship between personality variables prior to intervention and remaining abstinent for 12 months in people who have participated in a smoking cessation treatment program.

\section{Methods \\ Participants}

Participants were 125 workers at the University of Granada; they were recruited between 2009 and 2012 at an occupational health clinic providing smoking cessation treatment. Participants were included in the study providing they were 18 years of age or older, had an employment contract with the University of Granada, wanted to voluntarily participate in the treatment, and correctly filled in the pre-treatment evaluation measures. The exclusion criteria were as follows: history of major mental disorders (i.e., major depression, psychosis) or current psychotropic medication for psychiatric symptoms, concurrent dependence on other substances (cocaine, heroin, alcohol, etc.), and current use of medical prescription that are incompatible with the pharmacological treatment used (i.e., coronary heart disease, heart failure). Four of the treatment-seekers were excluded based on the exclusionary criteria used. Participants were informed about the aims of the study and provided signed informed consent. Ethical approval for this survey was obtained by the Ethics Committee of the Research University of Granada in Spain. The demographic and smoking behavior characteristics of the sample are displayed in table 1.

\section{Procedure}

An initial evaluation of the smokers was performed in a single session at the beginning of the program, in which the instruments described below were administered. The evaluation, treatment, and 3 , 6 and 12 month follow-up sessions of the program were implemented individually. 
Citation: López-Torrecillas F, Rueda MM, Pino CH, Fernández-García M (2015) Influence of Persistence or Cognitive (In)flexibility in Treatment to Quit Smoking. J Addict Addictv Disord 2: 006.

\begin{tabular}{|c|c|}
\hline Variables & Scores \\
\hline Age (mean and SD) & $46.91(8.15)$ \\
\hline Gender (N) & \\
\hline Male (Female) & $50(75)$ \\
\hline Education (N) & \\
\hline Primary/Secondary & 63 \\
\hline Tertiary & 43 \\
\hline Ph.D. & 19 \\
\hline Career (N) & \\
\hline Administrative and Service Personnel & 98 \\
\hline Academics/Researchers & 27 \\
\hline Years of smoking addiction (mean and SD) & $28.20(10.20)$ \\
\hline Number of daily cigarettes (mean and SD) & $19.86(8.95)$ \\
\hline Fagerström test scores (mean and SD) & $4.62(2.24)$ \\
\hline Cigarettes Brand (N) & \\
\hline Blonde & 105 \\
\hline Black Tobacco & 12 \\
\hline Rolling & 8 \\
\hline
\end{tabular}

Table 1: Base line demographic and smoking characteristics of the participants.

The program consisted of three phases. The first phase included a personalized number of sessions until abstinence was reached. During the first phase the cognitive-behavioral therapy was initiated by working towards developing stimulus control and self-control, and reducing tobacco consumption. Once the smoker had reduced tobacco consumption by $80 \%$, pharmacological treatment with varenicline was started for a period of 12 weeks. Varenicline is a nicotinic receptor partial agonist that effectively aids to smoking cessation. The treatment started with a daily dose of 0.5 $\mathrm{mg}$ for three days, and increases to a dose of $1 \mathrm{mg}$ twice a day until the end of the treatment. Prescription of varenicline was administered in line with the Food and Drug Administration's guidelines [26,27]. The cost of the medication was covered by the Prevention Service (Area Labor Medicine) of the University of Granada. If the participants did not reach abstinence, they abandoned the program. Participants who reached abstinence proceeded to the second phase of the program, which consisted of 6 sessions and aimed to maintain abstinence. It included training in problem solving, coping, and alternative behaviors to smoking. The third phase consisted of three follow-up sessions (at 3, 6, and 12 months). Participants were telephonically contacted by an independent assessor (blind to the study purpose and methods) at each endpoint (3,6 and 12 months after the start of the program). The purpose was to monitor their compliance with the treatment and their willingness to participate in the follow-up face-to-face assessments of smoking abstinence. Abstinence was assessed with a self-report of smoking behavior which was cross-validated with measurement of patients' co-oximetry hemoglobin levels. Participants' outcomes were coded as "relapse" or "abstinence". Abstinence was defined as not having smoked even once since the day the participant quit after gradual reduction of nicotine intake and pharmacological treatment. Relapse was defined as having smoked for 7 consecutive days in the past 3, 6 and 12 months, respectively $[28,29]$.

\section{Instruments}

Semi-structured interview for smokers [30]: This survey provides information about socio-demographic data, family history, and number of years of addiction, brand of cigarettes and level of dependence.

Fargerström Test for Nicotine Dependence [31]: This test is composed of 6 items with two or four response alternatives. Its factorial structure is consistent [32], and there is a Spanish version of the test [33].

Temperament and Character Inventory Revised (TCI-R) [4]: This questionnaire consists of 240 items ( 5 of them on validity), responded to on a 5-point Likert-type scale, and grouped in 4 temperament dimensions [Novelty Seeking, Harm Avoidance, Reward Dependence and Persistence] and 3 character dimensions [Self-directedness, Cooperativeness and Self-transcendence]. It has been validated in a general Spanish population [34] and has satisfactory psychometric properties [35].

\section{Statistical analysis}

A prospective longitudinal study was conducted in smokers (abstinence or relapse) who received multicomponent smoking-cessation therapy over a period of 12 months. Kaplan-Meier survival analysis [36] was performed to assess the probability of continued abstinence; log-rank tests were used to analyze differences in continued abstinence according to different categorical personality variables [low, medium, high scores on NS, HA, RD, PS, SD, C and ST]. This methodology has been used in the literature of applications of survival with sample sizes which are similar to the ones of our studio or even lower [37-39]. The survival analysis was conducted with the SPSS software package [40].

\section{Results}

\section{Abstinence outcome}

At the 3-month follow-up, 50 participants had relapsed during treatment, and 75 participants had maintained abstinence during treatment. At the 6-month follow-up, 63 participants had relapsed during treatment, and 62 participants had maintained abstinence during treatment. At the 12-month follow-up, 77 participants had relapsed during treatment, and 48 participants had maintained abstinence during treatment. Participants classified in each of these categories (relapse versus abstinence) at each of the three follow-ups did not significantly differ in demographic or baseline smoking behaviors characteristics (Table 2).

\section{Influence of personality variables in smoking relapse}

Survival analysis results (Table 3) revealed that PS had a significant influence on survival time, $\log \operatorname{Rank}=8.612 ; \mathrm{p}=0.013$. As the table shows, the group with low scores on PS, have less probability of relapse and a longer abstinence time than the group that presents medium and high scores on PS. Figure 1 and Table 3, illustrate the differences among the three groups in relation to the PS. We observe that the group that presents a low score has a $16.7 \%$ relapse rate compared to the groups that present medium and high scores, with relapse rates of $21.7 \%$ and $31.7 \%$, respectively. No differences in survival are observed in NS, HA, RD, SD, C and ST between the groups. 
Citation: López-Torrecillas F, Rueda MM, Pino CH, Fernández-García M (2015) Influence of Persistence or Cognitive (In)flexibility in Treatment to Quit Smoking $J$ Addict Addictv Disord 2: 006.

- Page 4 of 7 •

\begin{tabular}{|c|c|c|c|c|c|c|c|c|}
\hline \multirow{2}{*}{ Variables } & \multicolumn{5}{|c|}{ Abstinence } & \multirow[b]{2}{*}{$95 \%$ IC } & \multirow{2}{*}{ Log Rank } & \multirow{2}{*}{$p$} \\
\hline & Sample size & Number & Rates & Mean & Standard Error & & & \\
\hline \multicolumn{7}{|l|}{ Age } & \multirow{4}{*}{1.833} & \multirow{4}{*}{.400} \\
\hline $27-37$ & 16 & 11 & $68.8 \%$ & 6.73 & 1.54 & $3.71-9.74$ & & \\
\hline $38-48$ & 54 & 41 & $75.9 \%$ & 8.32 & .73 & $6.89-9.75$ & & \\
\hline $49-63$ & 55 & 43 & $78.2 \%$ & 7.07 & .72 & $5.66-8.48$ & & \\
\hline \multicolumn{7}{|l|}{ Gender } & \multirow{3}{*}{.247} & \multirow{3}{*}{$.61 \mathrm{~s}$} \\
\hline Male & 50 & 39 & $78 \%$ & 7.85 & .77 & $6.34-9.35$ & & \\
\hline Female & 75 & 56 & $74.7 \%$ & 7.38 & .63 & $6.14-8.61$ & & \\
\hline \multicolumn{7}{|l|}{ Education } & \multirow{4}{*}{2.255} & \multirow{4}{*}{.324} \\
\hline Elementary School & 63 & 47 & $74.6 \%$ & 7.06 & .69 & $5.70-8.42$ & & \\
\hline College Degree & 43 & 31 & $72.1 \%$ & 8,65 & .81 & $7.07-10.22$ & & \\
\hline Ph.D. & 19 & 17 & $89.5 \%$ & 7,00 & 1.23 & $4.58-9.42$ & & \\
\hline \multicolumn{7}{|l|}{ Occupation } & \multirow{4}{*}{1.318} & \multirow{4}{*}{.517} \\
\hline Janitorial & 18 & 15 & $83.3 \%$ & 7.40 & 1.23 & $4.99-9.80$ & & \\
\hline Administrative and Service Personnel & 80 & 58 & $72.5 \%$ & 7.95 & .62 & $6.72-9.17$ & & \\
\hline Teachers and Researchers & 27 & 22 & $81.5 \%$ & 6.68 & 1.03 & $4.66-8.70$ & & \\
\hline \multicolumn{7}{|l|}{ Cigarette Brand } & \multirow{4}{*}{3.931} & \multirow{4}{*}{$.14 c$} \\
\hline Blonde & 105 & 80 & $85 \%$ & 7.54 & .54 & $6.48-8.59$ & & \\
\hline Black & 12 & 9 & $75 \%$ & 5.90 & 1.35 & $3.25-8.53$ & & \\
\hline Rolling & 8 & 6 & $73.1 \%$ & 10.50 & 1.50 & $7.56-13.44$ & & \\
\hline \multicolumn{7}{|c|}{ Nicotine concentration mg per cigarette } & \multirow{4}{*}{1.619} & \multirow{4}{*}{.44} \\
\hline$<1$ & 23 & 20 & $85 \%$ & 6.45 & 1.10 & $4.29-8.61$ & & \\
\hline$>1<1.5$ & 99 & 72 & $75 \%$ & 7.90 & .56 & $6.82-8.99$ & & \\
\hline$>1.5 \quad 2$ & 3 & 3 & $73.1 \%$ & 7.00 & 2.65 & $1.81-12.19$ & & \\
\hline \multicolumn{7}{|l|}{ Number of cigarettes smoked daily } & \multirow{5}{*}{.186} & \multirow{5}{*}{.980} \\
\hline$<10$ & 20 & 17 & $85 \%$ & 7.94 & 1.14 & $5.71-10.17$ & & \\
\hline$>10<20$ & 72 & 54 & $75 \%$ & 7.44 & .64 & $6.19-8.70$ & & \\
\hline$>20<30$ & 26 & 19 & $73.1 \%$ & 7.58 & 1.13 & $5.37-9.78$ & & \\
\hline$>30$ & 7 & 5 & $71.4 \%$ & 7.60 & 2.69 & $2.32-12.88$ & & \\
\hline Fagerström Test Score & & & & & & & & \\
\hline$<6$ & 99 & 77 & $77.8 \%$ & 7.69 & .54 & $6.63-8.75$ & .296 & .586 \\
\hline$>7$ & 26 & 18 & $69.2 \%$ & 7.06 & 1.14 & $4.83-9.28$ & & \\
\hline Years of smoking & & & & & & & & \\
\hline$<10$ years & 14 & 12 & $85.7 \%$ & 7.17 & 1.47 & $4.28-10.05$ & & \\
\hline$<20$ years & 28 & 19 & $67.9 \%$ & 8.26 & 1.09 & $6.12-10.40$ & 2.560 & .464 \\
\hline$<30$ years & 40 & 33 & $82.5 \%$ & 8.21 & .82 & $6.60-9.83$ & & \\
\hline$>30$ years & 43 & 31 & $72.1 \%$ & 6.61 & .84 & $4.98-8.25$ & & \\
\hline
\end{tabular}

Table 2: Survival analysis results: effects of socio-demographic and smoking-related variables.

\section{Discussion}

The purpose of this study was to analyze the relationship between personality variables prior to the intervention and the maintenance of abstinence after 12 months follow-up in people who have undergone a smoking cessation treatment program.

Statistically significant differences were found on the PS variable. The abstinent group, with lower scores on persistence, had less probability of relapsing and a longer abstinence time than the groups with medium and high scores on persistence. The studies $[4,23,24]$ that analyze this variable indicate that low scores on this variable indicate perseverance in the behavior in spite of frustration and fatigue, impatience, ambition, perfectionism and involvement in the work. We can view the PS as the capacity to make an effort on difficult tasks, overcoming frustration and fatigue. This is supported to some extent by the reviewed literature that shows the connections between prefrontal cortex and the integration capabilities [18-22], which have to do with planned behavior, characterized by perseverance in spite of frustration and fatigue. High scores persistence indicate impatience, ambition, obsession and perfectionism $[4,23,24]$. In our study, the participants who showed medium or high scores on PS were more likely to relapse. These results agree with those obtained by other authors [21-26], who found that low PS is significantly associated with relapse. In these studies, persistence was evaluated by behavioral tasks. Another recent study [41] investigates the role of PS in predicting smoking cessation treatment outcomes in a sample of smokers 
Citation: López-Torrecillas F, Rueda MM, Pino CH, Fernández-García M (2015) Influence of Persistence or Cognitive (In)flexibility in Treatment to Quit Smoking. J Addict Addictv Disord 2: 006 .

- Page 5 of 7 •

\begin{tabular}{|c|c|c|c|c|c|c|c|c|}
\hline \multirow{2}{*}{ Variables } & \multirow{2}{*}{$\begin{array}{c}\text { Sample } \\
\text { size }\end{array}$} & \multirow{2}{*}{ Number of Abstinent during follow-up } & \multirow{2}{*}{$\begin{array}{c}\text { Number of } \\
\text { Relapse }(\%) \text { during follow-up }\end{array}$} & \multicolumn{2}{|c|}{ Time of abstinence } & \multirow{2}{*}{ IC (95\%) } & \multirow{2}{*}{$\begin{array}{l}\text { Log Rank } \\
\text { (Mantel-Cox) }\end{array}$} & \multirow{2}{*}{ p } \\
\hline & & & & Mean & Standard Error & & & \\
\hline \multicolumn{9}{|l|}{ NS } \\
\hline Low & 19 & 18 & $1(5.3 \%)$ & 7.56 & 1.22 & $5.17-9.94$ & \multirow{3}{*}{1.889} & \multirow{3}{*}{.389} \\
\hline Medium & 57 & 46 & $11(19.3 \%)$ & 8.24 & .65 & $6.97-9.58$ & & \\
\hline High & 49 & 31 & $18(36.7 \%)$ & 6.58 & .88 & $4.85-8.31$ & & \\
\hline \multicolumn{9}{|l|}{ HA } \\
\hline Low & 17 & 12 & $5(29.4 \%)$ & 6.42 & 1.29 & $3.89-8.94$ & \multirow{3}{*}{1.131} & \multirow{3}{*}{.568} \\
\hline Medium & 50 & 40 & $10(20.0 \%)$ & 7.78 & .75 & $6.31-9.24$ & & \\
\hline High & 58 & 43 & $15(25.9 \%)$ & 7.70 & .74 & $6.24-9.15$ & & \\
\hline \multicolumn{9}{|l|}{ RD } \\
\hline Low & 33 & 30 & $3(9.1 \%)$ & 8.53 & .83 & $6.92-10.15$ & \multirow{3}{*}{2.375} & \multirow{3}{*}{.305} \\
\hline Medium & 43 & 31 & $12(27.9 \%)$ & 6.61 & .89 & $4.87-8.35$ & & \\
\hline High & 49 & 34 & $15(30.6 \%)$ & 7.59 & .807 & $6.01-9.17$ & & \\
\hline \multicolumn{9}{|l|}{ PS } \\
\hline Low & 24 & 20 & $4(16.7 \%)$ & 10.55 & .70 & $9.18-11.93$ & \multirow{3}{*}{8.612} & \multirow{3}{*}{.013} \\
\hline Medium & 60 & 47 & $13(21.7 \%)$ & 6.79 & .70 & 5.41- 8.17 & & \\
\hline High & 41 & 28 & $13(31.7 \%)$ & 6.75 & .91 & $4.96-8.54$ & & \\
\hline \multicolumn{9}{|l|}{ SD } \\
\hline Low & 55 & 40 & $15(27.3 \%)$ & 7.25 & .76 & $5.77-8.73$ & \multirow{3}{*}{.342} & \multirow{3}{*}{.843} \\
\hline Medium & 49 & 42 & $7(14.3 \%)$ & 7.98 & .71 & $6.60-9.36$ & & \\
\hline High & 21 & 13 & $8(38.1 \%)$ & 7.23 & 1.50 & $4.29-10.17$ & & \\
\hline \multicolumn{9}{|l|}{ c } \\
\hline Low & 33 & 23 & $10(30.3 \%)$ & 6.87 & 1.00 & $4.90-8.84$ & \multirow{3}{*}{.979} & \multirow{3}{*}{.613} \\
\hline Medium & 42 & 35 & $7(16.7 \%)$ & 8.26 & .74 & $6.81-9.71$ & & \\
\hline High & 50 & 37 & $13(26.0 \%)$ & 7.35 & .83 & $5.72-8.98$ & & \\
\hline \multicolumn{9}{|l|}{ ST } \\
\hline Low & 36 & 26 & $10(27.8 \%)$ & 5.96 & .94 & $4.13-7.80$ & \multirow{3}{*}{4.294} & \multirow{3}{*}{.117} \\
\hline Medium & 37 & 30 & $7(18.9 \%)$ & 8.33 & .78 & $6.80-9.86$ & & \\
\hline High & 52 & 39 & $13(25.0 \%)$ & 8.05 & .79 & $6.51-9.59$ & & \\
\hline
\end{tabular}

Table 3: Results personality variables (TCI-R) on survival time.

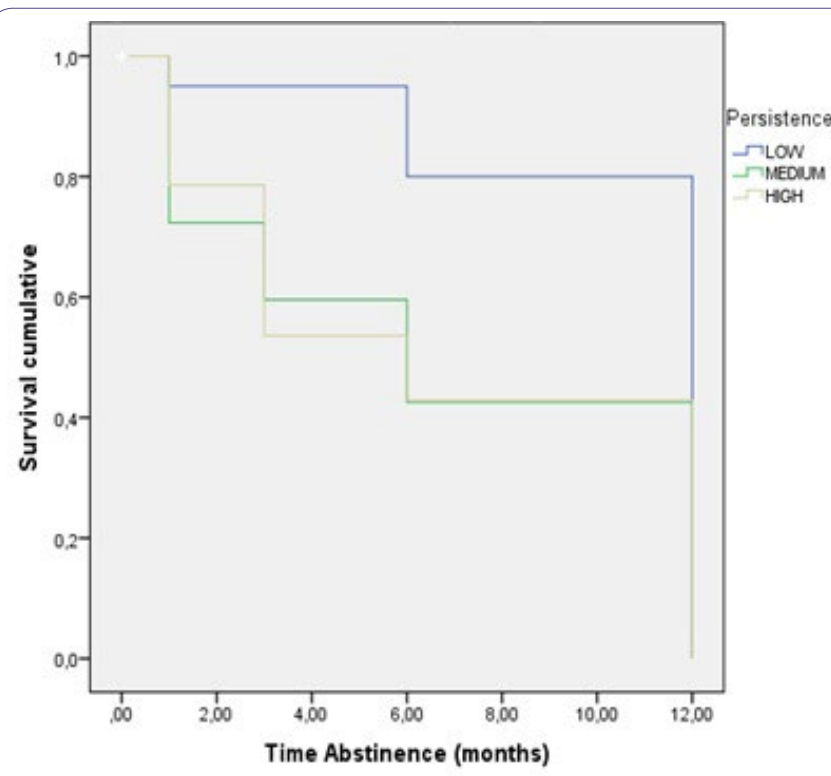

Figure 1: Function survival depending on persistence. participating in a clinical trial. PS was evaluated by means of the TCI-R self-report measure, and the findings showed that PS did not predict the smoking cessation outcome (for example, 24 hours after attempting to quit). We think these discrepancies (between the results of this study [41] and our results) are due to the study design and the type of analysis used. In our case, Kaplan-Meier survival analysis was performed to assess the probability of continued abstinence, and log-rank tests were used to analyze differences in continued abstinence as a function of personality variables. We used the Kaplan-Meier methodology because it is the most widely used approach for survival analysis in medicine [42]. The Kaplan-Meier approach has been made even more powerful by the development of statistical models that enable dichotomous outcomes to be used as dependent variables in multiple logistic regression analyses. Therefore, it is important to use adequate statistical designs to identify the variables that predict tobacco abstinence once the treatment is over and after a one-year follow-up, in order to design more effective intervention strategies.

We did not find that the rest of personality variables from the TCI-R (NS, HA, RD, SD, C and ST) had a significant effect on the length of abstinence (3, 6 and 12 months) between the groups. These results are consistent with those obtained by other studies [3,7-9], so that they 
Citation: López-Torrecillas F, Rueda MM, Pino CH, Fernández-García M (2015) Influence of Persistence or Cognitive (In)flexibility in Treatment to Quit Smoking. J Addict Addictv Disord 2: 006.

find personality differences between smokers and non-smokers, and in our study we found personality differences in the smokers who are quitting due to the treatment. Other studies [7-9] have found that NS is associated with initiation of tobacco consumption and dependence, or severity of addiction. Likewise, HA and RD have also been related to smoking initiation and the degree of dependence on nicotine [17]. However, in our study, PS showed a significant relationship with relapsing or remaining abstinent during a 12-month follow-up period. Therefore, there can be different patterns of tobacco abstinence depending on personality profile.

Finally, regarding the study limitations, we have to mention the possibilities for generalization. This study was carried out in a fairly optimal treatment context, as it is an internal service of the company (University of Granada), with easy access, and the patients come from the same organization. Therefore, we do not know whether these results can be generalized to other more varied types of patients or to other treatment conditions, such as healthcare centers or Regional Drug Dependence Centers.

\section{Conclusion}

Our study shows that personality has an influence on patterns of tobacco addiction and can affect long-term abstinence. It seems that there can be different patterns of tobacco abstinence depending on one's personality. Our results suggest that personality should be evaluated to predict the prognosis treatment. This would make possible to identify the population at the greatest risk of relapse during the treatment, in order to develop different and more accentuated intervention strategies that will help to prevent relapse.

\section{References}

1. Jaine R, Healey B, Edwards R, Hoek J (2014) How adolescents view the tobacco endgame and tobacco control measures: trends and associations in support among 14-15 year olds. Tob Control.

2. Observatorio Europeo de las Drogas y las Toxicomanías (EODT) (2014) Informe Europeo sobre las Drogas: Tendencias y Novedades.

3. Le Bon O, Basiaux P, Streel E Tecco J, Hanak C, et al. (2004) Personality profile and drug of choice; a multivariate analysis using Cloninger's TCl on heroin addicts, alcoholics, and a random population group. Drug Alcohol Depend 73: 175-182.

4. Cloninger CR, Svrakic DM, Przybeck TR (1993) A psychobiological model of temperament and character. Arch Gen Psychiatry 50: 975-990.

5. López-Torrecillas F, Nieto-Ruiz A, Velasco-Ortuño S, Lara-Fernández M, López-Quirantes EM, et al. (2014) The role of impulsivity in dropout from treatment for cigarette smoking. Compr Psychiatry 55: 1609-1613.

6. López-Torrecillas F, Perales JC, Nieto-Ruiz A, Verdejo-García A (2014) Temperament and impulsivity predictors of smoking cessation outcomes. PLoS One 9: e112440.

7. Mitchell SH, Wilson VB (2012) Differences in delay discounting between smokers and nonsmokers remain when both rewards are delayed. Psychopharmacology (Berl) 219: 549-562.

8. Spillane NS, Smith GT, Kahler CW (2010) Impulsivity-like traits and smoking behavior in college students. Addict Behav 35: 700-705.

9. Munafò MR, Yalcin B, Willis-Owen SA, Flint J (2008) Association of the Dopamine D4 Receptor (DRD4) gene and approach-related personality traits: meta-analysis and new data. Biol Psychiatry 63: 197-206.

10. Caggiula AR, Donny EC, Palmatier MI, Liu X, Chaudhri N, et al. (2009) The role of nicotine in smoking: a dual-reinforcement model. Nebr Symp Motiv 55: 91-109.
11. Hadjiconstantinou M, Neff NH (2011) Nicotine and endogenous opioids: neurochemical and pharmacological evidence. Neuropharmacology 60: 12091220.

12. Arinami T, Ishiguro H, Onaivi ES (2000) Polymorphisms in genes involved in neurotransmission in relation to smoking. Eur J Pharmacol 410: 215-226.

13. Benowitz NL (2010) Nicotine addiction. N Engl J Med 362: 2295-2303.

14. Munafò MR, Johnstone EC (2008) Genes and cigarette smoking. Addiction 103: 893-904.

15. Ebstein RP, Benjamin J, Belmaker RH (2000) Personality and polymorphisms of genes involved in aminergic neurotransmission. Eur J Pharmacol 410: 205-214.

16. Ohmoto M, Takahashi T, Kubota Y, Kobayashi S, Mitsumoto Y (2014) Genetic influence of dopamine receptor, dopamine transporter, and nicotine metabolism on smoking cessation and nicotine dependence in a Japanese population. BMC Genet 15:151.

17. Leventhal AM, Waters AJ, Boyd S, Moolchan ET, Heishman SJ, et al. (2007) Associations between Cloninger's temperament dimensions and acute tobacco withdrawal. Addict Behav 32: 2976-2989.

18. Gusnard DA, Akbudak E, Shulman GL, Raichle ME (2001) Medial prefrontal cortex and self-referential mental activity: relation to a default mode of brain function. Proc Natl Acad Sci USA 98: 4259-4264.

19. Bechara A, Dolan S, Denburg N, Hindes A, Anderson SW, et al. (2001) Decision-making deficits, linked to a dysfunctional ventromedial prefrontal cortex, revealed in alcohol and stimulant abusers. Neuropsychologia 39: 376-389.

20. Damasio AR (1996) The somatic marker hypothesis and the possible functions of the prefrontal cortex. Philos Trans R Soc Lond B Biol Sci 351: 14131420.

21. Abrantes AM, Strong DR, Lejuez CW, Kahler CW, Carpenter LL, et al. (2008) The role of negative affect in risk for early lapse among low distress tolerance smokers. Addict Behav 33: 1394-1401.

22. Brown RA, Lejuez CW, Kahler CW, Strong DR, Zvolensky MJ (2005) Distress tolerance and early smoking lapse. Clin Psychol Rev 25: 713-733.

23. Brown RA, Palm KM, Strong DR, Lejuez CW, Kahler CW, et al. (2008) Distress tolerance treatment for early-lapse smokers: rationale, program description, and preliminary findings. Behav Modif 32: 302-332.

24. Brown RA, Lejuez CW, Strong DR, Kahler CW, Zvolensky MJ, et al. (2009) A prospective examination of distress tolerance and early smoking lapse in adult self-quitters. Nicotine Tob Res 11: 493-502.

25. Brown RA, Reed KM, Bloom EL, Minami H, Strong DR, et al. (2013) Development and preliminary randomized controlled trial of a distress tolerance treatment for smokers with a history of early lapse. Nicotine Tob Res 15: 2005-2015.

26. Consejería para la Igualdad y Bienestar Social (2008) Junta de Andalucía Guía de Practica Clínica de Adicción al Tabaco.

27. New Drug for Smoking Cessation. (2004) US Food And Drug Administration, MD, USA.

28. Hughes JR, Keely JP, Niaura RS, Ossip-Klein DJ, Richmond RL, et al. (2003) Measures of abstinence in clinical trials: issues and recommendations. Nicotine Tob Res 5: 13-25.

29. Coleman T, Agboola S, Leonardi-Bee J, Taylor M, McEwen A, et al. (2010) Relapse prevention in UK Stop Smoking Services: current practice, systematic reviews of effectiveness and cost-effectiveness analysis. Health Technol Assess 14: 1-152.

30. López-Torrecillas F (1995) Estrés, afrontamiento, variables de personalidad y consumo de drogas. Universidad de Granada, Granada, Spain.

31. Heatherton TF, Kozlowski LT, Frecker RC, Fagerström KO (1991) The Fagerström Test for Nicotine Dependence: a revision of the Fagerström Tolerance Questionnaire. Br J Addict 86: 1119-1127. 
Citation: López-Torrecillas F, Rueda MM, Pino CH, Fernández-García M (2015) Influence of Persistence or Cognitive (In)flexibility in Treatment to Quit Smoking. J Addict Addictv Disord 2: 006

- Page 7 of $7 \bullet$

32. De Leon J, Becoña E, Gurpegui M, González-Pinto A, Diaz FJ (2012) The association between high nicotine dependence and severe mental illness may be consistent across countries. J Clin Psychiatry 63: 812-816.

33. Becoña E, Vázquez FL (1998) The Fagerström Test for Nicotine Dependence in a Spanish sample. Psychol Rep 83: 1455-1458.

34. Gutiérrez-Zotes JA, Bayón C, Montserrat C, Valero J, Labad A, et al. (2004) [Temperament and Character Inventory Revised (TCI-R). Standardization and normative data in a general population sample]. Actas Esp Psiquiatr 32: 8-15.

35. Pelissolo A, Mallet L, Baleyte JM, Michel G, Cloninger CR, et al. (2005) The Temperament and Character Inventory-Revised (TCl-R): psychometric characteristics of the French version. Acta Psychiatr Scand 112: 126-133.

36. Kleinbaum DG, Klein M (2005) Survival Analysis. A self-learning text. (3rd edn), Springer, New York, USA.
37. Cox DR, Okaes D (1984) Analysis of survival data. CRC Press, USA.

38. Hand DJ, Daly F, Lunn, AD, McConway K, Ostrowski E (1996) A Handbook of Small Data Sets CRC Press, USA.

39. Pytynia KB, Grant JR, Etzel CJ, Roberts DB, Wei Q, et al. (2004) Matchedpair analysis of survival of never smokers and ever smokers with squamous cell carcinoma of the head and neck. J Clin Oncol 22: 3981-3988.

40. IBM Corp. Released (2011). IBM SPSS Statistics for Windows, Version 20.0. Armonk, NY: Autor.

41. Kalman D, Hoskinson R, Sambamoorthi U, Garvey AJ (2010) A prospective study of persistence in the prediction of smoking cessation outcome: results from a randomized clinical trial. Addict Behav 35: 179-182.

42. Jekel JF, Katz DL, Elmore JG, Wild DMG (2007) Epidemiology, Biostatistics, and Preventive Medicine. (3rd edn), Saunders, Elsevier Inc. Philadelphia, USA. 